\title{
PERGURUAN TINGGI TANAH PAPUA DAN STRATEGI PENGEMBANGAN PENDIDIKAN TINGGI*
}

\author{
Ismail Suardi Wekke ${ }^{12}$, Muhammad Syahrul Kahar ${ }^{2}$, Irman Amri ${ }^{2}$ \\ ${ }^{1}$ Sekolah Tinggi Agama Islam Negeri (STAIN) Sorong, Papua Barat, Indonesia \\ ${ }^{2}$ Universitas Muhammadiyah Sorong, Papua Barat, Indonesia \\ Email: ismail@stain-sorong.ac.id, muhammadsyahrulkahar@gmail.com, \\ irmanamri1@gmail.com
}

\begin{abstract}
Higher education acts as the key institution to expand society. In addition, there is no reason to excuse. The higher education in Papua is among the pillar of Indonesian development. Therefore, the management and lectures should find formula to extend higher education in Papua to contribute for knowledge development. One key is partnership. Everyone should find opportunities from around the world to lengthen the practice. Moreover, the society will benefit from research activities.
\end{abstract}

Keywords: higher education, learning, development

“Kalau hendak seribu upaya, kalau tak hendak seribu dalih” (Pepatah Melayu)

\section{PENGANTAR}

Terkadang alasan geografis, Tanah Papua, kerap menjadi alasan. Jarak yang terbentang dari ibukota ke Papua dijadikan untuk tidak mau berjuang bersama dengan kolega di wilayah lain Tanah Air. Padahal, dengan fasilitas yang ada, serta perkembangan teknologi informasi saat ini, semuanya tidak dapat lagi menjadi alasan utama. Jarak dari manapun tetap sama saja. Kita memiliki waktu yang sama, berarti memiliki kesempatan yang sama.

Sudah saatnya, warga perguruan tinggi di Tanah Papua memiliki spirit untuk bersama-sama dengan seluruh warga perguruan tinggi Tanah Air dalam mencerdaskan kehidupan bangsa sebagaimana amanat Pembukaan Undang-undang Dasar. Alasan pendirian bangsa ini, paling tidak dua hal, keinginan untuk mencerdaskan kehidupan bangsa dan dengan kecerdasan itu berusaha untuk mewujudkan kesejahteraan rakyat.

Perguruan tinggi menjadi penjaga khazanah pengetahuan (Minhaji, 2013). Sehingga sekecil apapun kemampuan yang dimiliki akan menjadi sebuah upaya untuk turut berkontribusi bagi kemajuan ilmu pengetahuan. Alasan geografis ataupun lokasi, sekarang tidak bisa lagi menjadi persoalan. Perguruan tinggi Tanah Papua punya kesempatan yang

\footnotetext{
"Catatan dalam rangka pelaksanaan "Pelatihan Verifikator SINTA Tahun 2018”, Jayapura 8-9 Mei 2018.
} 
sama dengan seluruh perguruan tinggi untuk turut bersama-sama berkontribusi bagi kemanusiaan. Perguruan tinggi Papua justru berupaya untuk menjadi bagian dari akselerasi kemasyarakatan (Wekke, Hermawanto, \& Ashrori, 2016).

\section{POSISI PERGURUAN TINGGI PAPUA}

Tidak satupun perguruan tinggi Tanah Papua yang mencapai akreditasi A BAN-PT. ini menunjukkan bahwa belum ada pendidikan tinggi di pulau kita yang memenuhi standar di atas standar nasional. Sekaligus bermakna belum ada institusi yang unggul. Sementara institusi swasta dengan akreditasi B, hanya ada dua yaitu Universitas YAPIS Papua, dan Sekolah Tinggi Keguruan dan Ilmu Pendidikan Muhammadiyah Sorong. Ini menjadi agenda bersama untuk mendorong perguruan tinggi di Papua juga bisa bersanding dengan perguruan tinggi lain di tanah air.

Secara terbatas, 2017 lalu. Setidaknya satu event nasional dan empat internasional yang dilaksanakan di Sorong dan Raja Ampat. Mulai dari Rapat Kerja Fakultas Teknologi Industri Universitas Muslim Indonesia, juga Seminar Internasional dengan pelaksana Institut Teknologi Bandung, begitu juga Indonesia-Malaysia Forum on Peace and Development, serta Seminar Sambil Berlayar yang dilaksanakan dengan peserta Asia Tenggara. Diakhiri dengan International Conference yang dilaksanakan Perkumpulan Ahli dan Dosen Republik Indonesia. Paling tidak, dengan pelaksanaan rentetan acara tersebut menjadi sebuah kesempatan untuk mengenalkan Papua dan Papua Barat.

Selama ini, Papua distigmakan dengan ketidakamanan. Begitu pula dengan hanya mengenal persoalan Freeport semata. Padahal, Papua justru menjadi lumbung untuk melaksanakan kegiatan dan juga pengumpulan data penelitian. Papua juga punya kreativitas (Wekke, 2016). Pengembangan kurikulum dilakukan dengan inovasi (Wekke, 2015; Wekke, Siddin, \& Kasop, 2017). Demikian pula dalam ekspresi keberagamaan, tidak sebatas pada ibadah saja (Wekke, 2013; Wekke \& Gunaisah, 2015). Bahkan gerakan dakwah secara internal juga digiatkan (Wekke \& Sari, 2014).

\section{ARAH DAN STRATEGI PENGEMBANGAN}

Pertama, publikasi ilmiah. Dengan bentangan geografis dan keanekaragaman hayati Tanah Papua menjadi peluang untuk menerbitkan artikel dengan penciri originalitas. Hanya saja, kemahiran berbahasa selalu menjadi alasan. Maka, ini bisa diatasi dengan 
menerjemahkan karya-karya tulis yang ada. Sekali lagi, perlu sinergitas antar komponen bangsa. Sehingga kekurangan di sektor tertentu, dapat diatasi oleh komponen lain.

Kedua, riset. Untuk mendapatkan publikasi, maka muaranya adalah riset. Dengan riset yang terlaksana sesuai dengan ketentuan ilmiah, akan memudahkan untuk menyusun karya ilmiah yang dapat diterbitkan di jurnal bereputasi. Mewujudkan sebuah riset, diperlukan iklim akademik yang menumbuhsuburkan kemauan dan kemampuan riset. Untuk itu, tidak saja pimpinan perguruan tinggi tetapi juga diperlukan daya dukung dari dosen. Sementara tenaga kependidikan menjadi pendamping dosen dan mahasiswa dalam upaya mewujudkan visi masing-masing perguruan tinggi.

Kata kunci untuk ikhtiar itu adalah kemitraan. Dengan bersama-sama menjalankan sebuah penelitian akan memudahkan bagi individu untuk dapat berpartisipasi dalam pembangunan. Perguruan tinggi terkait juga dengan keadaan dan konteks masyarakat. Sehingga publikasi tidak bisa menjadi satu-satunya ukuran. Sehingga perguruan tinggi bisa saja dikelompokkan dalam kluster atau kategori yang masing-masing memiliki orientasi dan wawasan yang tidak seragam.

Penguatan kelembagaan secara bersama-sama dengan penguatan individual dilaksanakan (Wekke, 2012). Sementara itu, adat dan agama serta tradisi lokal harus menjadi acuan untuk pengembangan (Wekke, 2017). Sementara harmoni dan toleransi menjadi bagian dari pembelajaran (Mokodenseho \& Wekke, 2017). Untuk itu, akselerasi pendidikan tinggi hanya bisa dilakukan jikalau wawasan bersama dapat diwujudkan. Ini bukan pekerjaan yang sukar tetapi juga mudah dilaksanakan. Dengan civitas akademika Papua berjalan bersama dan saling menyapa, maka apapun tantangan dan halangan dapat diatasi secara bersama.

\section{PENUTUP}

Pendidikan bukanlah menjadi tanggungjawab manajemen semata. Tetapi menjadi tugas dan kewenangan seluruh komponen bangsa. Bahkan juga tanggung jawab manusia secara keseluruhan. Maka, tidak perlu ada sekat berkaitan dengan identitas dalam kaitan menggerakkan perguruan tinggi. Manusia, sebagai identitas. Jikalau itu sudah dipenuhi, maka semuanya memiliki tugas untuk memajukan perguruan tinggi. Papua membuktikan bahwa identitas keagamaan hanyalah urusan privat semata. Identitas keagamaan yang menyatu dengan perguruan tinggi tidak menjadi alasan tidak saling menyapa. Bahkan, 
dalam beberapa hal, perguruan tinggi tidak menjadikan itu sebagai patokan. Semata-mata hanya soal identitas pribadi semata.

\section{DAFTAR PUSTAKA}

Minhaji, A. (2013). Tradisi akademik di perguruan tinggi. Suka-Press.

Mokodenseho, S., \& Wekke, I. S. (2017). Toleransi Beragama dan Pembelajaran Agama Islam. PROSIDING, 1(1), 67-75.

Wekke, I. S. (2012). Pembelajaran dan identitas muslim minoritas (upaya penguatan lembaga pendidikan Islam Papua Barat). Jurnal Ilmu Pendidikan Al-Rabwah, VI (2), 75-94.

Wekke, I. S. (2013). Masjid di Papua Barat: Tinjauan ekspresi keberagamaan minoritas Muslim dalam arsitektur. El-Harakah (Terakreditasi), 15(2), 124-149.

Wekke, I. S. (2015). Tradisi pesantren dalam konstruksi kurikulum bahasa Arab di lembaga pendidikan minoritas muslim Papua Barat. KARSA: Journal of Social and Islamic Culture, 22(1), 20-38.

Wekke, I. S. (2016). Religious education and empowerment: study on pesantren in muslim minority West Papua. MIQOT: Jurnal Ilmu-ilmu Keislaman, 37(2).

Wekke, I. S. (2017). Islam dan adat: tinjauan akulturasi budaya dan agama dalam masyarakat Bugis. Analisis: Jurnal Studi Keislaman, 13(1), 27-56.

Wekke, I. S., \& Gunaisah, E. S. (2015). Identitas dan ekspresi keberagamaan Nelayan muslim: Masyarakat pesisir Raja Ampat Papua Barat. In Prosiding Seminar Nasional Kelautan dan Perikanan (Vol. 10).

Wekke, I. S., \& Sari, Y. R. (2014). Tifa Syawat dan Entitas Dakwah dalam Budaya Islam: Studi Suku Kokoda Sorong Papua Barat. THAQAFIYYAT: Jurnal Bahasa, Peradaban dan Informasi Islam, 13(1), 163-186.

Wekke, I. S., Hermawanto, A., \& Ashrori, M. (2016). Keberagamaan Mahasiswa Di Perguruan Tinggi Wilayah Minoritas Muslim. Ulul Albab, 17(2), 135.

Wekke, I. S., Siddin, S., \& Kasop, I. (2017). Pesantren, Madrasah, Sekolah, dan Panti Asuhan. At-Tajdid: Jurnal Ilmu Tarbiyah, 6(1). 